\title{
CARACTERÍSTICAS CLÍNICAS E FATORES ASSOCIADOS À CRONIFICAÇÃO EM INDIVÍDUOS ACOMETIDOS POR CHIKUNGUNYA NO MUNICÍPIO DE FEIRA DE SANTANA, BAHIA.
}

\author{
Nadja Layane Gomes Santiago ${ }^{1}$; Murilo Fernandes de Souza ${ }^{2}$; Kayque Neves da Silva ${ }^{3}$; \\ Melissa Barreto Falcão ${ }^{4}$ e Erenilde Marques de Cerqueira ${ }^{5}$ \\ 1. Bolsista FAPESB, Graduando em Medicina, Universidade Estadual de Feira de Santana, e-mail: \\ nadjalayane@hotmail.com \\ 2. Bolsista FAPESB, Graduando em Medicina, Universidade Estadual de Feira de Santana, e-mail: \\ murilofes@hotmail.com \\ 2. Bolsista FAPESB, Graduando em Medicina, Universidade Estadual de Feira de Santana, e-mail \\ kayque sn@hotmail.com \\ 4. Médica infectologista, e-mail: melissa.falcao@hotmail.com \\ 5. Orientadora, Departamento de Saúde, Universidade Estadual de Feira de Santana, e-mail: eremarques@,fsonline.com.br
}

PALAVRAS-CHAVE: chikungunya, epidemiologia, cronificação.

\section{INTRODUÇÃO}

Chikungunya é uma arbovirose causada pelo vírus chikungunya (CHIKV) transmitida aos humanos através da picada das fêmeas dos mosquitos Aedes aegypti e Aedes albopictus infectados (Schuffenecker et al, 2006).

Em 2017, foram registrados 185.854 casos prováveis de febre de chikungunya no país. Em 2018, até a semana epidemiológica (SE) 7 (31/12/2017 a 17/02/2018), foram registrados 7.406 casos prováveis, com uma incidência de 3,6 casos/100 mil habitantes (Brasil, 2018).

A maioria dos indivíduos infectados pelo CHIKV desenvolve sintomas, alguns estudos mostram que até 70\% apresentam infecção sintomática (Brasil, 2017). O CHIKV pode causar doença aguda, subaguda e crônica (Sergon et al., 2008). A fase aguda ou fase febril é caracterizada principalmente por febre de início súbito e surgimento de intensa poliartralgia, geralmente acompanhada de dores nas costas, rash cutâneo (presente em mais de $50 \%$ dos casos), cefaleia e fadiga., com duração de 15 dias. Alguns pacientes evoluem para a fase subaguda, na qual a febre normalmente desaparece, podendo haver persistência ou agravamento da artralgia, com duração de até três meses. A doença crônica é definida pela persistência de sintomas por mais de três meses. (Brito, 2016; Brasil, 2017). Os principais fatores de risco para a cronificação são: idade acima de 45 anos, significativamente maior no sexo feminino, desordem articular preexistente e maior intensidade das lesões articulares na fase aguda (Brasil, 2017).

A chikungunya tem caráter epidêmico com elevada taxa de morbidade associada à artralgia persistente, tendo como consequência a redução da produtividade e da qualidade de vida. O risco de transmissão da doença no país é grande, haja vista que o mosquito Aedes pode ser encontrado em praticamente todo território nacional, e a situação é considerada como uma emergência epidemiológica para o município e para o Brasil. Por se tratar de uma doença de introdução recente no país, cuja produção científica local e experiência clínica são incipientes, existem inúmeras dúvidas relacionadas com a "história clínica natural" da enfermidade. Dessarte, o objetivo do presente estudo foi descrever os aspectos clínicos da fase aguda e identificar possíveis fatores associados à cronificação da doença nos indivídios acometidos por Chikungunya no período de 2014 a 2018, no município de Feira de Santana, Bahia.

\section{METODOLOGIA}

Desenho do Estudo: Pesquisa de natureza quantitativa, do tipo corte transversal, observacional, restrospectivo. Teve como campo de estudo a cidade de Feira de Santana, Bahia, 
e local de estudo a Divisão de Vigilância Epidemiológica Municipal. O estudo envolveu pacientes com infecção por CHIKV, atendidos no ambulatório de infectologia do Centro de Referência de Chikungunya em Feira de Santana, no Estado da Bahia, no período de outubro de 2017 a abril de 2018. Participaram da pesquisa 66 indivíduos. Foram considerados requisitos de inclusão pacientes com sintomas de Chikungunya, com diagnóstico confirmado por critério clínico e laboratorial (CHIKV IgM e/ou IgG), de ambos os sexos e maiores de 18 anos. Foi construído um Termo de Consentimento Livre e Esclarecido (TCLE) e assinado pelos participantes que concordaram em participar da pesquisa. Os pacientes com Chikungunya foram avaliados retrospectivamente, por meio de seus dados clínicos e laboratoriais coletados de formulário padronizado, tendo como base as informações presentes no prontuário médico, complementadas por entrevista durante consulta médica. As seguintes variáveis foram consideradas: sexo, idade, cor da pele, escolaridade, ocupação, local do atendimento inicial, características clínicas da fase aguda, medicamentos usados na fase aguda, tempo de doença e comorbidades. Considerou-se a classificação determinada pelo Ministério da Saúde para as fases aguda, subaguda e crônica da Chikungunya (Brasil, 2017). Os dados foram tabulados e analisados graficamente por meio do software Excel 2016. A presente pesquisa foi submetida ao Comitê de Ética em Pesquisa com Seres Humanos - CEP/UEFS e só foi iniciada a coleta dos dados após a aprovação deste, obedecendo a Resolução 466/12 do Ministério da Saúde.

\section{RESULTADOS}

No período de outubro de 2017 a abril de 2018 foram atendidos 66 casos de Chikungunya no ambulatório de infectologia do centro de referência em Feira de Santana. Como se pode observar na tabela 1, houve predominância do sexo feminino, correspondendo a $83,3 \%(n=55)$ dos casos. Em relação a faixa etária no início do quadro, 56,1\% estavam na faixa de 50-69 anos, 28,8\% entre 30-49 anos, 10,6\% maiores de 70 anos e 4,5\% menores de 30 anos. Quanto a cor da pele, 42,4\% se declaram brancos, 30,3\%, negros e 27,3\%, pardos.

Tabela 1. Distribuição de casos de Chikungunya segundo a faixa etária da fase aguda e sexo, Feira de Santana, 2014-2018.

\begin{tabular}{lcclcc}
\hline & $\mathbf{N}$ & $\mathbf{\%}$ & & $\mathbf{N}$ & $\mathbf{\%}$ \\
\hline Sexo & & & Faixa etária & & \\
Masculino & 11 & 16,7 & $<29$ anos & 3 & 4,5 \\
Feminino & 55 & 83,3 & $30-49$ anos & 19 & 28,8 \\
& & & $50-69$ anos & 37 & 56,1 \\
& & & $>70$ anos & 7 & 10,6 \\
\hline
\end{tabular}

O grau de escolaridade mais frequente nesses pacientes foi ensino fundamental incompleto em $31,8 \%$, seguido de ensino médio completo em $28,8 \%$ e superior completo em $15,1 \%$. Das mulheres atendidas, uma era gestante e estava no $3^{\circ}$ trimestre.

Quanto a data de início dos sintomas, $72,7 \%$ dos pacientes tiveram início do quadro no ano de 2015, com predomínio nos meses de abril, maio e junho. A maioria dos pacientes $(71,2 \%)$ procuraram atendimento inicial em policlínicas, $16,7 \%$ em hospitais privados e os $12 \%$ restantes procuraram atendimento em Unidades de Saúde da Família (USF), Secretaria Municipal da Saúde (SMS) e hospitais municipais. A maioria $(95,4 \%)$ não necessitou de internamento.

Quanto ao quadro clínico no período da fase aguda, 89,4\% $(\mathrm{n}=59)$ apresentaram febre. Destes, $45,8 \%$ não souberam ou não aferiram a temperatura, e dos que aferiram $(n=32)$, foi alta $\left(>38,5^{\circ} \mathrm{C}\right)$ em $87,5 \%$ e baixa a moderada $\left(\leq 38,5^{\circ} \mathrm{C}\right)$ em $12,5 \%$, tendo duração menor ou igual a 7 dias em $74,5 \%$ dos pacientes. A maioria $(87,9 \%)$ manifestou calafrios. Todos pacientes 
referiram artralgia, sendo intensa em $90,9 \%$ dos casos. Foram acometidas mais de 4 articulações em 95,4\% ( $\mathrm{n}=63)$ dos pacientes, sendo as articulações mais envolvidas as das mãos, pés, tornozelos e punhos. O edema estava associado em pelo menos uma articulação em $89,4 \%$ dos casos e mialgia ocorreu em $89,4 \%$ dos pacientes. A frequência dos sintomas na fase aguda da doença nesses pacientes pode ser observada no gráfico 1 . Das alterações urinárias, relatadas por 13 pacientes $(19,7 \%)$, a mais comum foi disúria $(n=12)$.

Os achados clínicos confirmaram dados da literatura. Segundo a Organização Mundial da Saúde (2008), os sintomas mais frequentes são febre alta, artralgias e cefaleia. A febre geralmente é alta e é pouco responsiva aos antipiréticos (Simon, 2011).

Gráfico 1. Frequência das condições clínicas da fase aguda da Chikungunya em pacientes acometidos no período de 2014 a 2018. Feira de Santana, Bahia.

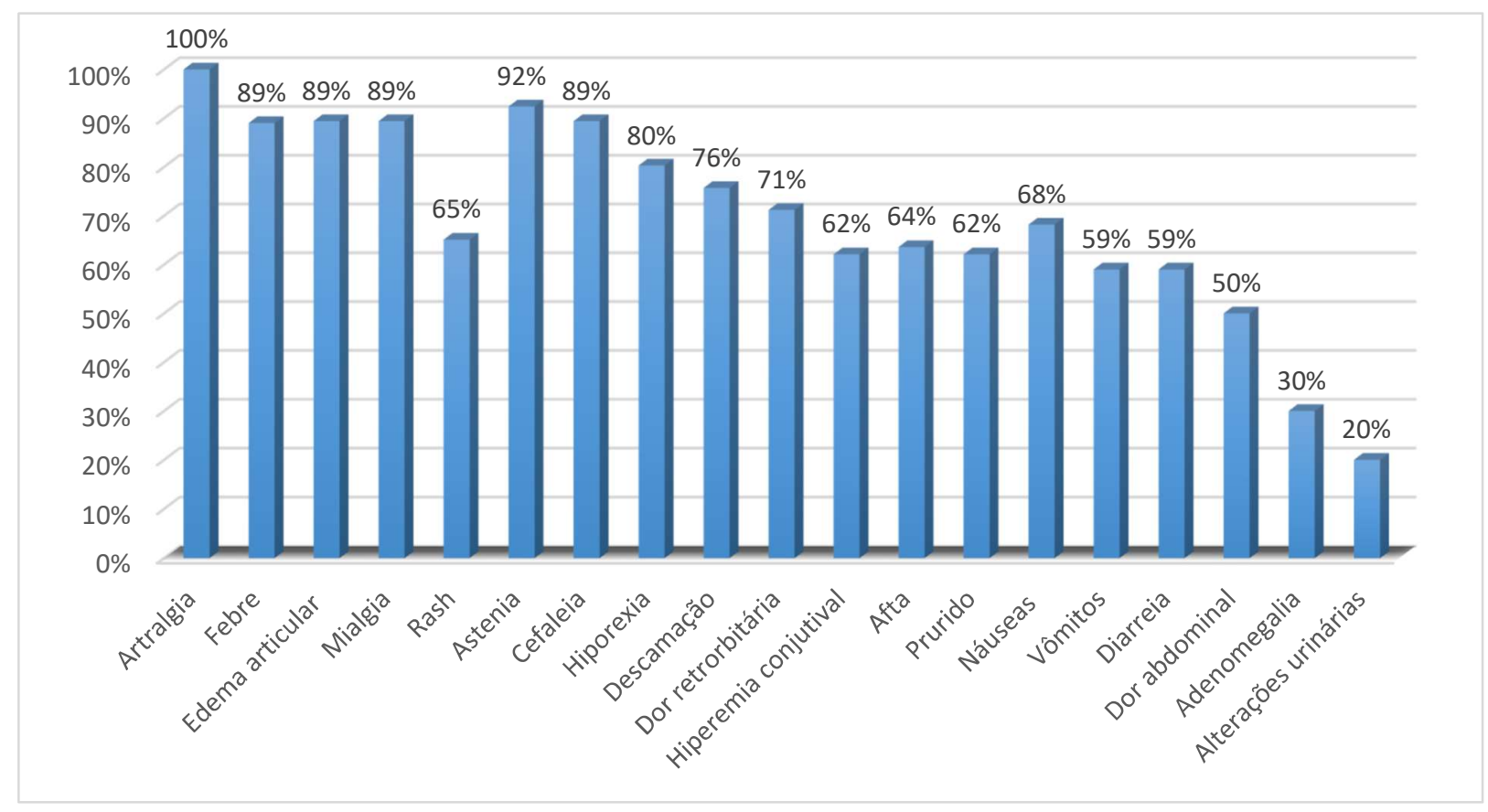

Quanto ao tratamento medicamento instituído na fase aguda, somente $48,4 \%(n=31)$ fizeram de acordo com o indicado pelo Ministério da Saúde (2017) e da Sociedade Brasileira de Reumatologia (2017), utilizando somente analgésicos comuns associados ou não a opioides fracos. O uso de antiinflamatórios não hormonais (AINH) e corticoides, que não são indicados para esta fase (Brito, 2016; Marques, 2017 e Brasil, 2017), podendo inclusive contribuir para evolução da doença para fase crônica, foram utilizados por $29,7 \%$ e $36,5 \%$ dos pacientes, respectivamente.

\section{CONCLUSÃO}

O presente estudo, cujo objetivo foi descrever os aspectos clínicos da fase aguda dos indivíduos acometidos por Chikungunya e identificar possíveis fatores associados à cronificação da doença, encontrou dados relevantes e que ratificaram o que já vinha sido descrito na literatura. A alta taxa de artralgia intensa na fase aguda, a maior prevalência na população economicamente ativa e o risco potencial de cronificação, revela a Chikungunya como causa importante de incapacidade física e laboral, impactando de forma significativa na qualidade de vida dos pacientes acometidos. No estudo pôde-se observar também a alta taxa de tratamento medicamentoso inadequado na fase aguda da doença, o que, além de não resolver 
de maneira eficiente o problema do indivíduo a curto prazo, pode contribuir para a evolução para a doença crônica. Esses achados ratificam a necessidade de se investir em informação, comunicação e educação em saúde da população em relação à Chikungunya, doença emergente e prevalente em nosso meio, mas ainda desconhecida por muitas pessoas, para que ocorra uma mobilização social na prevenção da doença, assim como para o reconhecimento do quadro clínico e dos riscos da automedicação. É imprescindível a atualização dos profissionais de saúde em relação ao reconhecimento da doença e manejo adequado, especialmente da fase aguda, o que está associado a uma menor chance de cronificação da doença. Também foram encontrados outros prováveis fatores envolvidos na evolução arrastada da doença, como idade avançada, artralgia intensa na fase aguda, sexo feminino, presença de comorbidades, principalmente as doenças reumatológicas. Percebe-se a necessidade de que novos estudos clínicoepidemiológicos sejam realizados com amostras maiores, na tentativa de se conhecer mais a doença, seus fatores de cronificação e sua tendência local, assim como a importância de se adotar na prática nas diversas unidades de saúde os protocolos de manejo da Chikungunya preconizados pelo Ministério da Saúde. Dessa forma, será possível promover uma melhor atenção e assistência à saúde das pessoas acometidas pela doença, visando minimizar a dor e as sequelas, bem como melhorando a qualidade de vida.

\section{REFERÊNCIAS}

BRASIL. Chikungunya: manejo clínico / Ministério da Saúde, Secretaria de Vigilância em Saúde, Departamento de Vigilância das Doenças Transmissíveis. - Brasília: Ministério da Saúde, 2017.

BRASIL. Ministério da Saúde. Boletim Epidemiológico Secretaria de Vigilância em Saúde. Volume 49, $\mathrm{N}^{\circ}$ 9, março de 2018.

BRASIL. MINISTÉRIO DA SAÚDE. Secretaria de Vigilância em Saúde. Boletim Epidemiológico. Volume 48, $\mathrm{N}^{\circ}$ 7, 2017.

BRITO, C. A. et al. Pharmacologic management of pain in patients with Chikungunya: a guideline. Rev. Soc. Bras. Med. Trop., v. 49, n. 6, p. 668-679, Nov./Dec. 2016.

MARQUES, C. D. L. et al. Recommendations of the Brazilian Society of Rheumatology for diagnosis and treatment of chikungunya fever. Part 1 - Diagnosis and special situations. Revista Brasileira de Reumatologia. Volume 57, edição 2, 2017, Páginas 421-437.

SCHUFFENECKER, I. et al. Genome microevolution of chikungunya viruses causing the Indian Ocean outbreak. PLoS Medicine.v.3, n.7, p.1058-1070, e263, 2006.

SERGON, K. et al. Seroprevalence of Chikungunya virus (CHIKV) infection on Lamu Island, Kenya, October 2004.Am J Trop Med Hyg.v.78, n.2, p.333-337,fev. 2008.

SIMON, F., Javelle, E., Oliver, M. et al. Chikungunya Virus Infection. Current Infectious Disease Reports. June, 2011. 13:218. Disponível em: https://doi.org/10.1007/s11908-0110180-1

WORLD HEALTH ORGANIZATION. Guidelines on clinical management of chikungunya fever. 2008. 